\title{
Scientometric research in South Africa and successful policy instruments
}

Prof Anastassios Pouris, Director: Institute for Technological Innovation, University of Pretoria email: anastassios.pouris@up.ac.za

\begin{abstract}
This document provides an analysis of scientometric research in South Africa and it discusses sources of growth in the country's research literature in general. South Africa is identified to have limited expertise in the field revealed mainly during the last decade. However, the country is ranked $21^{\text {ST }}$ in the world among the countries publishing in the journal Scientometrics and it is the only African country with such a standing in the field. Identification of the forces affecting positively the growth in the number of research publications in the country indicates that the primary incentive fuelling the recent growth is the new funding formula in the country which subsidizes the universities by more than R100 000 for each publication that their staff produces. The increase in the number of journals indexed in the ISI Thomson Reuters database and the incorporation of social sciences at the NRF have also affected the growth of research publications, but to a lesser extent.
\end{abstract}

\section{Key words}

\section{Scientometrics; South Africa; incentives; impact on research}

\section{Introduction}

Since Vassily V. Nalimov coined the Russian term 'scientometrics' ('naukometriya')( Nalimov and Mulchenko, 1969), the term has grown to define research in quantitative aspects of science and technology. The term gained recognition by the founding in 1978 of the journal Scientometrics by Tibor Braun in Hungary. Even though scientometric studies are not without their critics (Roland 2007; Leydesdorff 2008) scientometrics is currently an indispensable part of science and technology policy monitoring and assessment studies (Jeenah et al 2008); studies related to the structure and dynamics of science (Schubert et al 2010; Mackenzie 2000, Mansfield 1995); impact assessments (King 2004; Lubango et al 2009; Inglesi-Lotz et al 2011) and others.

In South Africa the first scientometric investigations were undertaken during the second half of the 1980s. The term was unknown to policy makers at the time. Twenty years later, researchers publish in the field and government authorities commission relevant research and use scientometrics for the development of science and technology indicators ( $\mathrm{NACl} 2002$ ). 
The objective of this document is to describe the growth of scientometrics research in the country and provide a recent scientometric profile of the country.

\section{Methodology}

For the objective of this investigation we use scientometrics firstly in order to observe the state of scientometrics research in the country at the particular level of specialization, and secondly in order to position the country's overall research through the overall production of scientific literature in an international context.

The use of scientometric indicators (e.g. number of publications) is considered as one of the most effective methods in assessing research performance. It allows comparisons of different disciplines; comparisons of countries, changes over time and others which are not possible through other methods such as peer review.

The philosophy underlying the use of scientometric indicators as performance measures is based on De Solla Price's (1975) statement that "for those who are working at the research front, publication is not just an indicator but, in a very strong sense, the end product of their creative effort"

A prerequisite for any scientometric analysis is the existence of a appropriate database. While there are a number of specialised databases (e.g. Chemical Abstracts; Compendex; Embase etc) for this effort we utilize the Institute for Scientific Information (ISI) Thomson Reuters family of databases (citation indices). The ISI family of databases is commonly used as information platform for these types of analyses and assessments because of their multidisciplinary and interdisciplinary character and the selectivity used in the choice of indexed journals. The combined databases cover comprehensively the most prestigious journals in the world in all fields of research endeavours.

The ISI databases are particularly useful in the South Africa context as the Department of Education has identified the ISI indexed journals for subsidy purposes and universities provide incentives to their researchers to publish in ISI indexed journals.

The identified platform is interrogated for the identification of South African authors publishing in the field of scientometrics. Scientometrics articles have been identified according to a number of key words and articles published in a relevant set of journals. The set of journals used - those most related to the journal Scientometrics - is as follows: Scientometrics; Journal of Informetrics; Research Evaluation; Annual Review of Information Science and Technology; Journal of the American Society for Information Science and Technology; Journal of Information Science; Journal of Documentation; Information Processing \& Management and Research Policy.

The key words used were: scientometric*, bibliometric*, "citation analysis*", "citation performance*"; "citation assessment*"; "patent* analysis"; "patent* performance"; patent* activit*"; "article* analysis"; "publication* performance"; publication* analysis"; publication* activit*; technol* performance"; "scien* quantitative assessment"; "assess* scien*"; "scientific 
productivity*"; "impact factor"; research and mapping; "journal assess*"; "journal evaluat*"; "research performance*, where the ${ }^{*}$ denotes a variable string of characters.

These key words cover areas of citations studies and research performance analysis, library information science and information retrieval (Uzun 2002)

The identified set of scientometric related articles was analyzed in order to identify trends over time, institutions participating in the research, and similar.

Similarly, we identified all articles with at least one South African address for the period 20012011 in the journal Scientometrics and we analyzed the identified set.

Finally we identified the country's number of research publications and world share for the period 1981 to 2010 and reviewed the policy instruments that may have affected the country's relevant productivity.

The results appear in the next section.

\section{Scientometrics Research in South Africa}

In South Africa the first scientometrics study was produced in 1987 on contract for the Foundation for Research Development (FRD) now the National Research Foundation (NRF).

The report (Pouris et al 1987) addressed the question: Is research in the field of physics good and research in the field of plant sciences unsatisfactory in South Africa?

A large-scale peer evaluation of researchers initiated by the FRD at the time indicated that physicists in the country had higher evaluation ratings and plant scientists' lower evaluation ratings than those in other disciplines.

Based on the intuitive assumption that scientists are assessed according to their research activity and performance, the results of the FRD assessment led to the argument that: physics research was stronger than plant sciences research in the country.

The report utilised scientometrics in order to assess that assertion. The indicators used included the South African contribution to world scientific literature in the particular disciplines, the country's rating according to publication output per discipline and the citations per paper for South Africa in the given fields in comparison to the world norms. The National Science Foundation's (NSF) Science Literature Indicators Database compiled by Computer Horizon Inc Research was used for the scientometric analysis.

Contrary to the beliefs at the time the report provided evidence that botany research was much stronger than physics in South Africa.

The word scientometric was also appeared in the FRD's structure during 1989 as the organisation established the "Scientometric Advisory Service" in order to receive relevant science policy advice. 
Figure 1 shows the number of South African publications in the field of scientometrics. It is apparent that only in the mid-2000 the field started receiving attention and support. Since 1985 the field was producing only one or two publications per year. During 200917 publications were published with at least one author from South Africa.

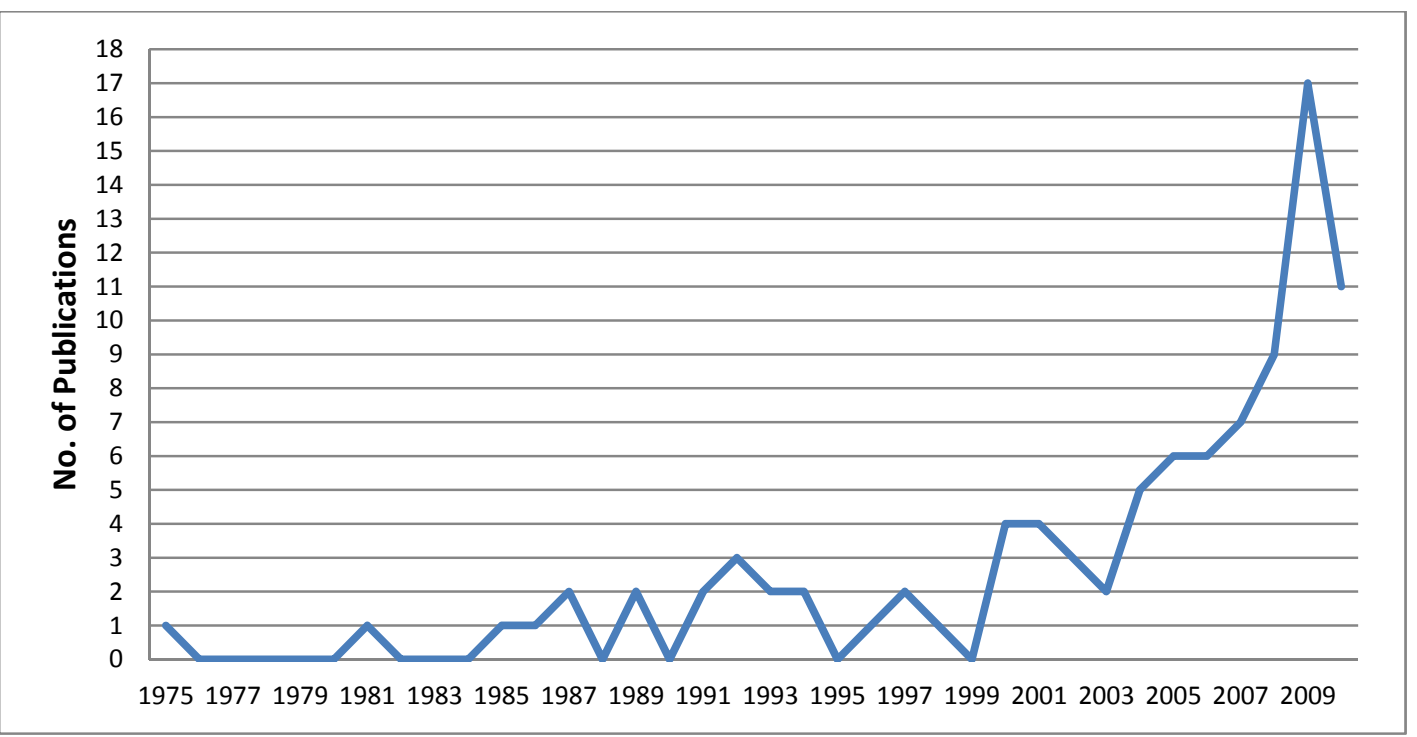

Figure 1: SA Scientometrics Publications 1975-2010

Most of the articles appeared in the journal Scientometrics (28) and the South African Journal of Science (12) (Table 1)

Table 1: Journals publishing most SA articles

\begin{tabular}{|lc|}
\hline Journal & Articles \\
\hline Scientometrics & 28 \\
\hline South African Journal of Science & 12 \\
\hline Journal of Information Science & 7 \\
\hline Journal of the American Society for Information Science and Technology & 7 \\
\hline Information Processing \& Management & 6 \\
\hline Research Policy & 4 \\
\hline
\end{tabular}

Table 2: Producers of Scientometric Research in South Africa

\begin{tabular}{|lcc|}
\hline & Articles & $\%$ \\
\hline University of Pretoria & 38 & 0.39 \\
\hline University of Kwa-Zulu Natal & 12 & 0.12 \\
\hline University of Witwatersrand & 9 & 0.09 \\
\hline
\end{tabular}




\begin{tabular}{|lcr|}
\hline Stellenbosch University & 8 & 0.08 \\
\hline University of Cape Town & 7 & 0.07 \\
\hline University of South Africa & 6 & 0.06 \\
\hline National Research Foundation & 6 & 0.06 \\
\hline Other & 12 & 0.12 \\
\hline
\end{tabular}

Table 2 and Figure 2 show the South African institutions which publish scientometric related research articles. The University of Pretoria appears to have produced 39\% of the country's relevant research. The University of KwaZulu Natal follows with 12\%.

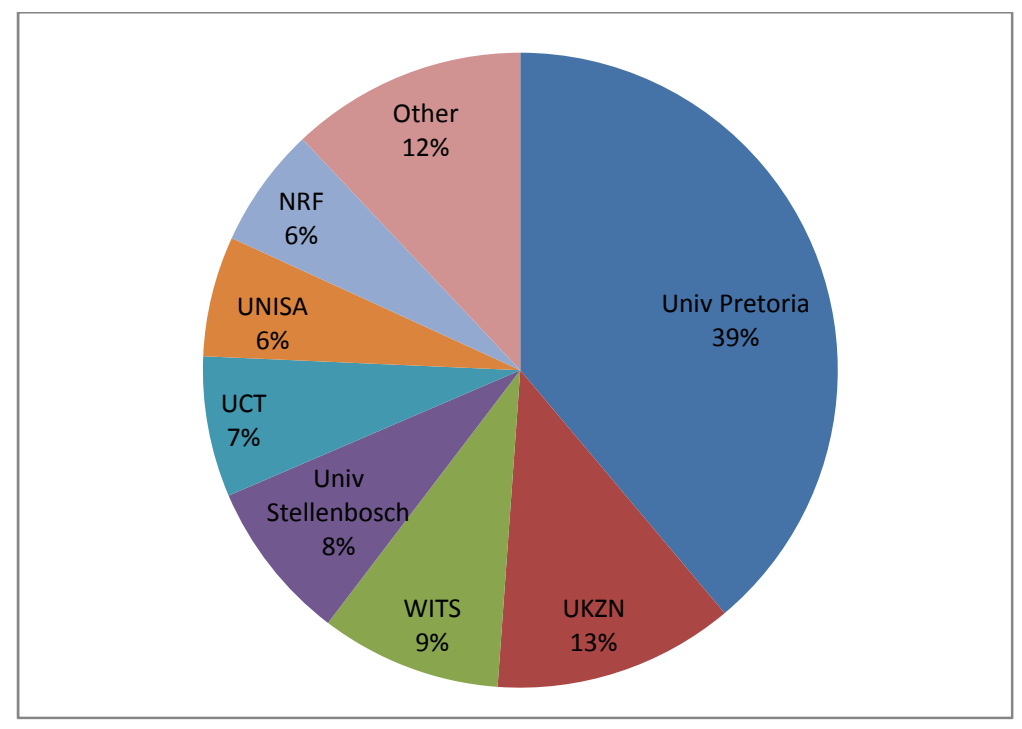

Figure 2: Producers of SA Scientometrics Research

Co-authorship analysis identified that out of the 98 articles 26 were co-authored with at least one author from another country. Eleven articles were co-authored with authors from the USA and four with authors from the Netherlands.

Table 3 shows that South Africa ranks $21^{\text {st }}$ in the world according to the number of publications in the core journal of the field scientometrics. This is substantially higher from the $37^{\text {th }}$ position that South Africa occupies according to total number of publications in the National Science Indicators database of ISI Thomson Reuters (2004-2008). The table further shows that no other African country is publishing the journal Scientometrics. Our original list indicates that during the period Nigeria and Egypt appeared with only one publication each. 
Table 3: Country Ranking according to Number of publications in the journal Scientometrics (2001 to March 2011)

\begin{tabular}{|llllll|}
\hline Rank & Country & $\begin{array}{l}\text { No of } \\
\text { publications }\end{array}$ & Rank & Country & $\begin{array}{l}\text { No of } \\
\text { publications }\end{array}$ \\
\hline $\mathbf{1}$ & USA & 194 & 16 & BRAZIL & 34 \\
\hline $\mathbf{2}$ & BELGIUM & 152 & 17 & FINLAND & 31 \\
\hline $\mathbf{3}$ & SPAIN & 141 & 18 & JAPAN & 31 \\
\hline $\mathbf{4}$ & PEOPLES R CHINA & 122 & 19 & SWEDEN & 30 \\
\hline $\mathbf{5}$ & NETHERLANDS & 107 & 20 & SWITZERLAND & 26 \\
\hline $\mathbf{6}$ & ENGLAND & 106 & 21 & SOUTH AFRICA & 22 \\
\hline $\mathbf{7}$ & GERMANY & 93 & 22 & DENMARK & 21 \\
\hline $\mathbf{8}$ & HUNGARY & 87 & 23 & IRAN & 19 \\
\hline $\mathbf{9}$ & INDIA & 74 & 24 & ISRAEL & 19 \\
\hline $\mathbf{1 0}$ & TAIWAN & 61 & 25 & AUSTRIA & 16 \\
\hline $\mathbf{1 1}$ & FRANCE & 47 & 26 & RUSSIA & 14 \\
\hline $\mathbf{1 2}$ & SOUTH KOREA & 40 & 27 & TURKEY & 14 \\
\hline $\mathbf{1 3}$ & AUSTRALIA & 39 & 28 & MEXICO & 12 \\
\hline $\mathbf{1 4}$ & CANADA & 39 & 29 & CROATIA & 11 \\
\hline $\mathbf{1 5}$ & ITALY & 39 & 30 & NORWAY & 11 \\
\hline
\end{tabular}

\section{Successful Policy Instruments}

The introduction of scientometrics in the country not only has emphasised the importance of quantitative studies of science and technology for policy objectives but also has contributed in the setting of national targets and in using quantitative measures for subsidy purposes.

Currently the country's universities receive subsidies (among others) according to the number of articles they produce annually.

Figure 3 shows the number of publications and the country's share in the ISI Thomson Reuters citation indices for the period 1981-2009 (National Science Indicators). It is noticeable the rapid increase of the country's publications from around 4000 per year in the early 2000 to 7000 publications in the end of the decade. Similarly the country's share in the world literature increased from $0.5 \%$ in the late 90 s and early 2000 s to 0.6 in the end of the decade. 


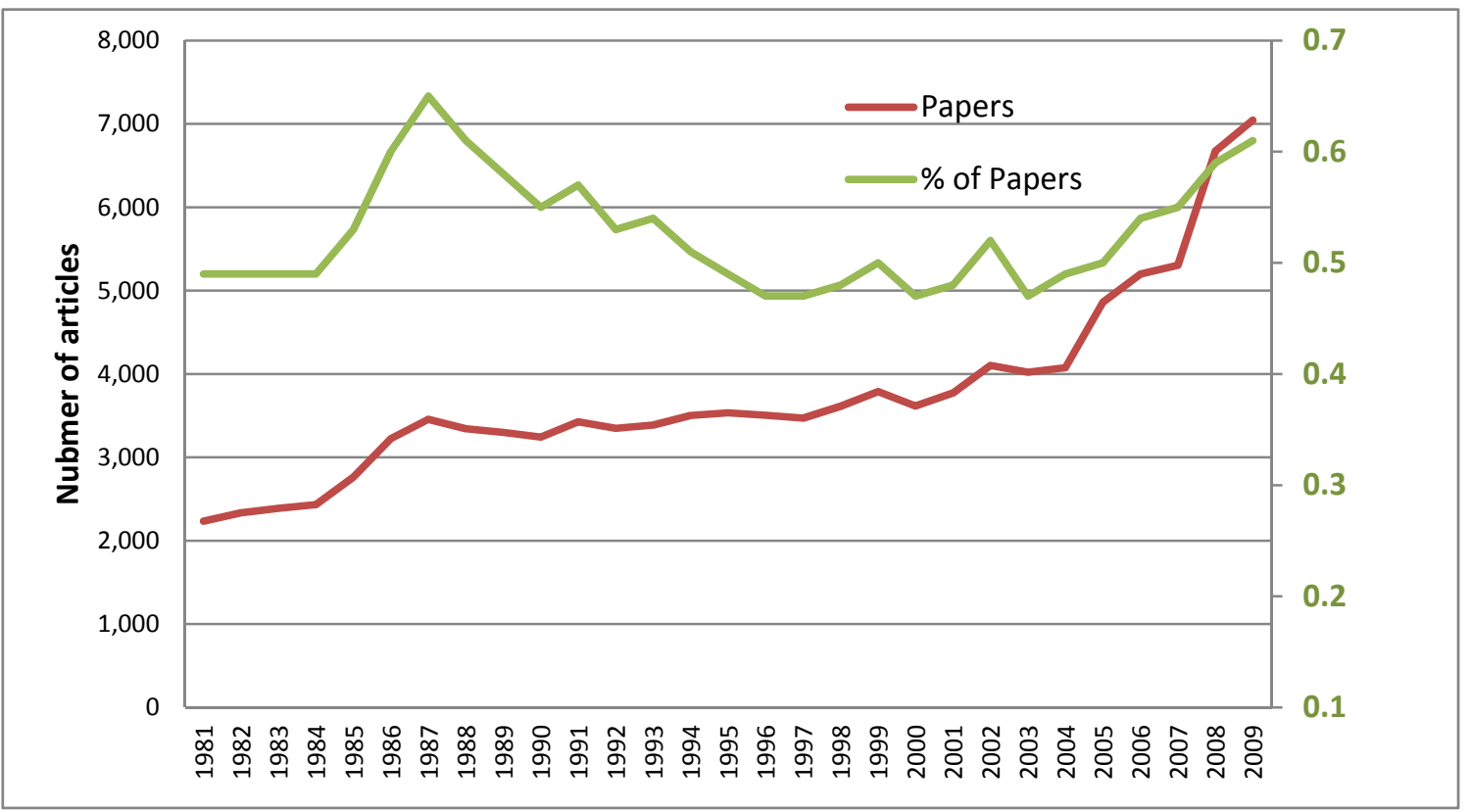

Figure3: Number and World share of South African publications (all disciplines)

From a policy perspective it is important to identify the forces that led to the substantial increase in the number of country's publications during the last decade.

Kahn (2011) investigating the country's publications for two periods (1990-1994 and 20042008) suggests that the growth during the period is the result of a multiplicity of factors. He states "there are greater rewards for publishing; there is a shift toward health science fields with high publication rates, there are more South African journals indexed by the Web of Science in which to publish, there may be more PhD students available to assist with research and the system is more open for co-publication with foreign parties". Furthermore, he speculates that collaboration is the most important factor affecting the growth in the number of articles in the country. However, the collaboration argument cannot explain the radical increase in the number of publications after 2004 (Fig 3). International collaboration increased from $7.9 \%$ of the total number of SA articles in 1980 to $47.2 \%$ during 2010 . However, most of the growth took place during 1995-2000 and 1990-1995 (Fig 4). 


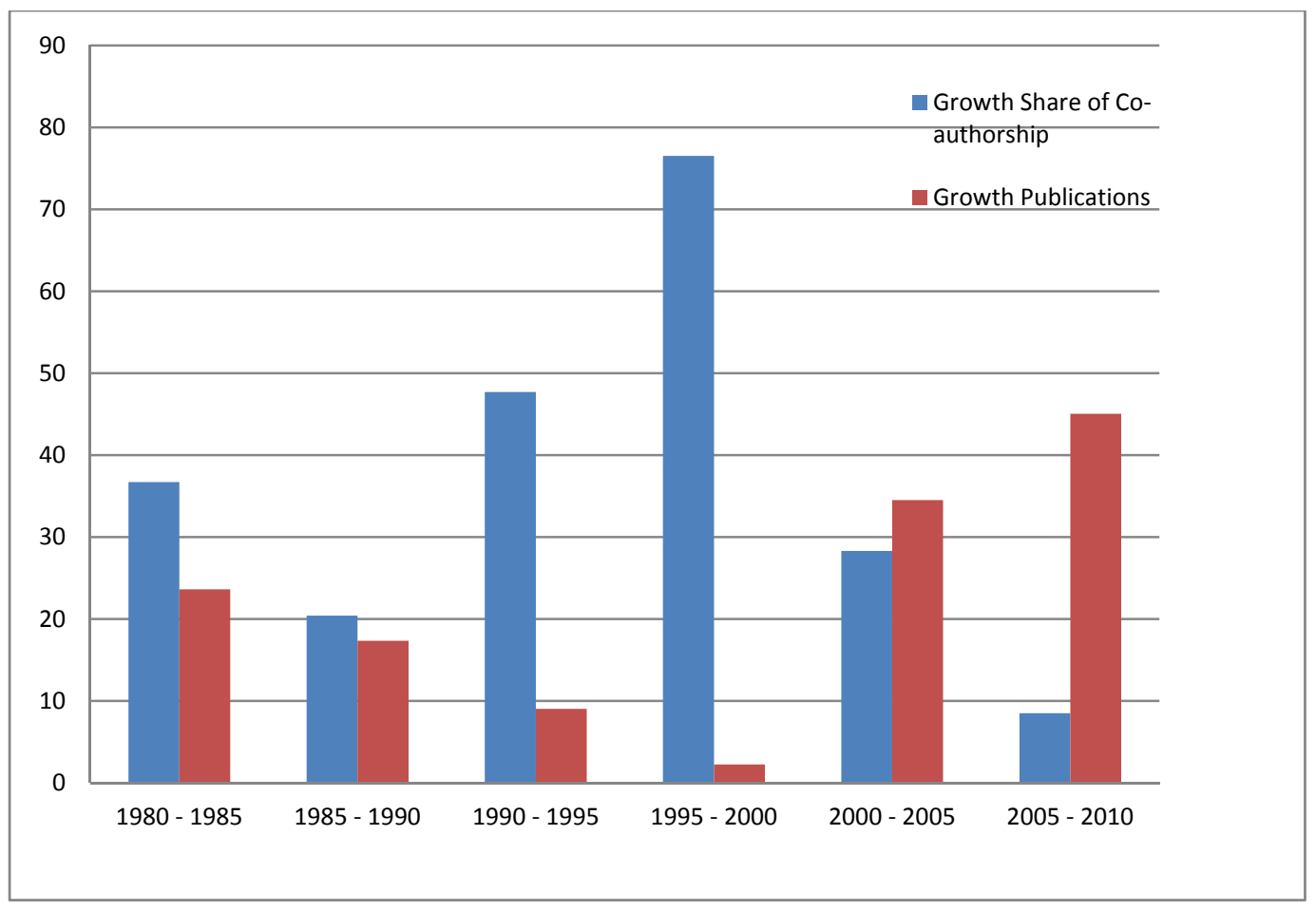

Figure 4: Growth in share of SA co-authorship articles and number of publications

Inglesi-Lots et al (2011) used the "before/after control impact (BACl) method" in order to identify the impact of the NRF researcher rating system on the social sciences publications in the country. The authors identified that the number of social sciences' publications were increased by $24.7 \%$ after 2001 because of the NRF's intervention. While the authors explain the increase of articles in the social sciences it should be mentioned that the discipline was contributing only $10.6 \%$ of the country's publications at that time (2008).

An estimation of the number of South African articles published in the journals added in the databases during 2008 (700 additional journals) by ISI-Thomson Reuters indicates that this is only approximately 450 articles per year.

Similarly (out of the 22 scientific disciplines in the National Science Indicators database) clinical medicine and plant and animal sciences contributed $16 \%$ of the country's articles each (200408 ) and the increase in the number of those articles contributed $26 \%$ ( 780 articles) of the extra 3000 articles in the period 2003-2008. The remaining number of articles increases across all scientific disciplines.

The across the board increases in the number of publications indicates that the increases were the result of a factor which was introduced during the early 2000s and was affecting all scientific disciplines. The obvious intervention was the new funding framework (NFF) for higher education institutions. The NFF for higher education institutions was published in terms of the 
Higher Education Act, No. 101 of 1997, in the Government Gazette (No. 1791) on 9 December 2003 and was implemented in the 2004/05 financial year.

The NFF supports financially the higher education institutions (among others) according to their research outputs (number of publications and number of post-graduates) (Steyn et al 2007). It becomes apparent that the particular policy instrument is bringing the desirable effect - an increase in the number of the country's publications.

\section{Discussion}

This document provides analysis of scientometric research in South Africa and it discusses sources of growth in the country's research literature. Scientometrics related research appeared sporadically in the relevant literature up to 2000. Since then the field appears to have taken off with 17 articles having appeared during 2009. The universities of Pretoria and of KwaZulu Natal appear to be the main producers of relevant literature with the universities of the Witwatersrand, Stellenbosch and Cape Town following with small differences in their publication profiles. The International Journal of Scientometrics and the South African Journal of Science appear to be the main vehicles for reporting research results in the field from South Africa. Analysis of the corporate addresses of the authors in the journal Scientometrics during the last decade indicates that South Africa is ranked 21st in the world. This is a substantially higher ranking than the $37^{\text {th }}$ position that the country occupies according to the total number of publications in the ISI Thomson Reuters databases. Furthermore, it is identified that rarely other African countries publish in the core journal of the field - i.e. in the International Journal of Scientometrics.

The growth in the number of publications in the field of scientometrics is not an isolated phenomenon. All South African scientific disciplines grew substantially during the period. The number of South African publications increased from 4000 per year during 2003 to just above 7 000 during 2009 (Fig 5). An analysis of the various factors affecting the number of publications indicates that the primary incentive fuelling the recent growth is the NFF which subsidizes the universities by more than R100 000 for each publication that their staff produces. The increase in the journal coverage of the ISI Thomson Reuters has also contributed in the increase of the publications but to a lesser extent. Similarly the incorporation of social sciences in the NRF stable of funding disciplines has influenced the publication profile of the field. International collaboration may have contributed in the gradual increase of the number of publications during the 1990' after the political sanctions were lifted.

\section{Acknowledgements}

An earlier version of the article has been presented as key note address at the $13^{\text {th }}$ International Society of Scientometrics and Informetrics (ISSI) 2011 Conference, Durban, South Africa; 4 to 8 July 2011 


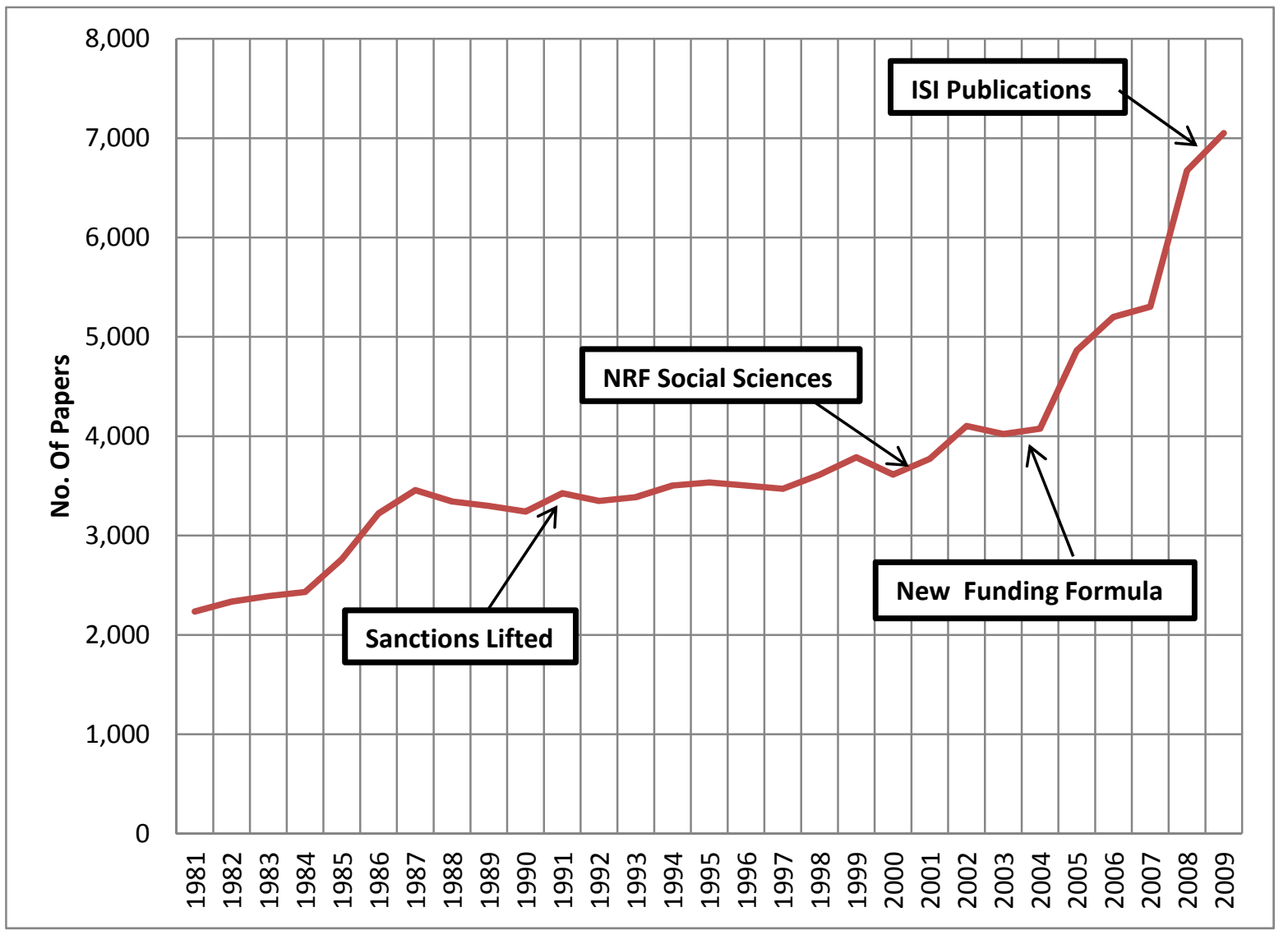

Figure 5: Number of SA publications and critical events

\section{References}

De Solla Price D. (1970). The productivity of research scientists, in Yearbook of science and the future, Encyclopaedia Britannica Inc. University of Chicago, Chicago

Inglesi-Lotz, R. and Pouris, A. (2011). Scientometric impact assessment of a research policy instrument: the case of rating researchers on scientific outputs in South Africa. Scientometrics 88(3):747-760

Jeenah, M. and Pouris, A. (2008). South African Research in the Context of Africa and Globally. SA J of Science 104 (9/10), 351-354

Kahn, M. (2011). A bibliometric analysis of South Africa's scientific outputs - some trends and implications. South African Journal of Science 107 (1/2):1-6

King, D. A. (2004). The scientific impact of nations: what different countries get for their research spending. Nature 430: 311-316. 
Leydesdorff, L. (2008). Caveats for the Use of Citation Indicators in Research and Journal Evaluation. Journal of the American Society for Information Science and Technology. 59(2), 278287

Lubango, L.M., Pouris, A. (2009). Is patenting activity impeding the academic performance of South African university researchers?. Technology in Society. 31:315-324.

Mansfield, E. (1995). Academic research underlying industrial innovations: sources, characteristics and financing. Review of Economics and Statistics 77(1):55-65.

Nalimov, V. V., Mulchenko, M. Z. (1969). Naukometriya. Izuchenie Razvitiya Nauki kak Informatsionnogo Protsessa. [Scientometrics. Study of the Development of Science as an Information Process], Nauka, Moscow, (English translation: 1971. Washington, D.C.: Foreign Technology Division. U.S. Air Force Systems Command, Wright-Patterson AFB, Ohio. (NTIS Report No.AD735-634).

Mackenzie, S. (2000). Scientific silence: AIDS and African Americans in the medical literature. American Journal of Public Health. 90, 1145-1146.

NACl (2002). South African Science and Technology: Key Facts and Figures 2002. National Advisory Council on Innovation, Pretoria

Pouris, A. and Pouris, A. (1987). Physics and Botany Research in South Africa. Report to Foundation for Research Development, Pretoria

Roland, E. (2007). On the Use and Abuse of Bibliometric Indicators: a critique of Hix's Global Ranking of Political Departments. European Political Scienc.e 6 (3):306-314

Schubert, T. and Sooryamoorthy, R. (2010). Can the centre-periphery model explain patterns of international scientific collaboration among threshold and industrialised countries? The case of South Africa and Germany. Scientometrics. 83 (1) 181-203

Steyn, W.G.A. and de Villiers, P. A. (2007). Public funding of higher education in South Africa by means of formulae. Council of Higher Education accessed during March 2011 at http://www.google.co.za/search?hl=en\&source=hp\&q=PUBLIC+FUNDING+OF+HIGHER+EDUCA TION+IN+SOUTH+AFRICA\&btnG=Google+Search

Uzun, A. (2002). Productivity ratings of institutions based on publication in Scientometrics, Informetrics and Bibliometrics 1981-2000. Scientometrics. 53(3) 297-307 